\title{
SÍNTESE ENZIMÁTICA DE MONOÉSTERES DE ETILA CATALISADA POR CÉLULAS ÍNTEGRAS DE FUNGO FILAMENTOSO EM REATOR DE LEITO FIXO
}

\author{
E. L. P. FARIA ${ }^{1}$, J. D. RIVALDI ${ }^{1}$, A. K. F. CARVALHO ${ }^{1}$, H. F. de CASTRO ${ }^{1}$ \\ ${ }^{1}$ Escola de Engenharia de Lorena - USP, Departamento de Engenharia Química \\ E-mail para contato: danielrivaldi@gmail.com
}

\begin{abstract}
RESUMO - Células do fungo filamentoso Mucor circinelloides URM 4182, com elevada atividade lipolítica, foram imobilizadas in situ em poliuretano e utilizadas diretamente como biocatalisador na síntese de monoésteres de etila a partir da reação de etanólise do óleo de coco. Os experimentos foram conduzidos em reator de leito fixo empacotado com $15 \mathrm{~g}$ do biocatalisador, operando em fluxo contínuo (tempo espacial de $68 \mathrm{~h}$ ) a $35^{\circ} \mathrm{C}$. A comparação do desempenho do reator para substratos contendo diferentes proporções molares de etanol/ óleo indicou que etanol em excesso na razão molar 8:1 (etanol/óleo) permitiu alcançar elevadas conversões em ésteres $(82,5 \pm 3,2 \%)$ sem redução relevante da conversão por 16 dias. Os elevados teores de monoglicerídeos $(9,23 \pm 0,5 \mathrm{~m} / \mathrm{m} \%)$ e diglicerídeos $(3,45 \pm 0,3 \mathrm{~m} / \mathrm{m} \%)$ demonstram a necessidade de estudos complementares diante das variáveis que ainda podem ser otimizadas.
\end{abstract}

\section{INTRODUÇÃO}

O uso de processos enzimáticos em substituição à catálise química tradicional desponta como uma alternativa viável para o desenvolvimento de processos eficientes visando à obtenção de produtos sustentáveis. As lipases são, muito provavelmente, o grupo de enzimas versáteis, com a mais ampla faixa de utilidade como biocatalisadores (Singh; Mukhopadhyay, 2012). Estas enzimas se caracterizam por serem amplamente especificas e de elevada regio ou enantio seletividade (Kapoor; Gupta, 2012). Esta ampla especificidade por substratos pode parecer contraditória para uma enzima, mas é a consequência da heterogeneidade natural de triglicérideos, diglicérideos ou monoglicerídeos de ácidos graxos com comprimento de cadeia e grau de saturação muito diferente. Algumas lipases são bastante robustas e podem ser utilizadas numa vasta variedade de sistemas de reação (Christopher et al., 2014).

Entretanto, muitas aplicações industriais dos biocatalisadores são ainda limitadas pelo alto custo de produção e baixa produtividade (Fukuda et al., 2009). Como forma de reduzir estes custos, diversos estudos estão sendo direcionados na utilização de células íntegras. Grande parte desses estudos reporta a utilização das células íntegras na forma imobilizada, baseado na técnica de imobilização espontânea das células em suporte adequado ao longo do cultivo (Yoshida et al., 2012). A biomassa celular imobilizada pode ser utilizada diretamente na reação de interesse e reutilizada diversas vezes. Esta estratégia tem apresentado resultados promissores empregando diferentes microrganismos produtores de lipase intracelular para mediar reações de hidrólise, esterificação e principalmente transesterificação de óleos vegetais visando à obtenção do biodiesel (Subhash; Mohan, 2011). No entanto, são escassos os trabalhos que descrevem a utilização desse 
sistema imobilizado em biorreatores operando em fluxo contínuo, principalmente adotando a rota etanólica nas reações de transesterificação de óleos vegetais.

A utilização de biorreatores operando em sistema de fluxo contínuo oferece inúmeras vantagens quando comparado com o processo em batelada, principalmente por possibilitar o controle automático, ser mais fácil de operar e favorecer o controle de qualidade do produto em relação principalmente a estabilidade do processo. Além disso, a configuração dos biorreatores operado em fluxo contínuo minimiza os possíveis efeitos danosos às células imobilizadas devido ao stress físico causado pela agitação mecânica do sistema em batelada. Entretanto, cada modelo reacional necessita de um estudo detalhado, incluindo variáveis importantes do processo, tais como: atividade catalítica do biocatalisador, razão molar entre os componentes do meio reacional, dimensões do reator, fluxo de alimentação do meio reacional, entre outros (Jin et al., 2008; Andrade et al., 2012 Yoshida et al., 2012).

Estudos anteriores (Andrade et al., 2012) indicaram que mediante a utilização de um biocatalisador de baixo custo (células integras de Mucor circinelloides imobilizadas) e o emprego de um sistema simples, foi possível sintetizar biodiesel em regime descontínuo e fluxo contínuo a partir da etanólise do óleo de babaçu. Apesar do elevado tempo de meia-vida do biocatalisador (40 dias) a conversão obtida em fluxo contínuo foi $40 \%$ menor que a obtida em regime descontínuo. Desta forma, o presente trabalho teve como objetivo avaliar a influência de diferentes razões molares entre óleo de coco e etanol na síntese enzimática de ésteres de etila, bem como estudar a influência da dimensão do reator no desempenho do processo.

\section{MATERIAIS E METÓDOS}

\subsection{Materiais}

Os experimentos foram realizados empregando a linhagem do fungo Mucor circinelloides URM 4182 adquirida da coleção de culturas da Micoteca URM (CCB/UFPe). Como suporte de imobilização foi utilizado espumas de poliuretano comercial (Scotch-Brite ${ }^{\mathrm{MR}}$ ) cortadas em cubos de $6 \mathrm{~mm}$, com densidade aparente de $0,02 \pm 0,01 \mathrm{~g} / \mathrm{cm}^{3}$ e diâmetro médio de poros de $0,36 \pm 0,14$ $\mathrm{mm}$. Como materiais de partida foram utilizados etanol anidro (99\%, Cromoline) e óleo de coco (Frescoco) tendo uma composição aproximada em ácidos graxos de: 5,6\% Caprílico, 5,0\% Cáprico, 45,8\% Láurico, 18,6\% Mirístico, 8,8\% Palmítico, 3,4\% Esteárico, 5,6\% Oleico, 0,9\% Linoleico. Terc-butanol (Cromoline) foi utilizado como solvente.

\subsection{Cultivo e imobilização do fungo}

Os cultivos foram conduzidos em frascos Erlenmeyer de $250 \mathrm{~mL}$ contendo $100 \mathrm{~mL}$ de meio de cultura líquido de composição óleo de oliva (Carbonell) $30 \mathrm{~g} / \mathrm{L}$, peptona (Himedia) 70g/L, $\mathrm{NaNO}_{3}$ (Vetec) $1 \mathrm{~g} / \mathrm{L}, \mathrm{KH}_{2} \mathrm{PO}_{4}$ (Synth) $1 \mathrm{~g} / \mathrm{L}$ e $\mathrm{MgSO}_{4} \cdot 7 \mathrm{H}_{2} \mathrm{O}$ (Vetec) $0,5 \mathrm{~g} / \mathrm{L}$. Os frascos previamente esterilizados, foram inoculados assepticamente com $1 \times 10^{6}$ esporos $/ \mathrm{mL}$ do fungo, juntamente com 100 cubos de espumas de poliuretano, e incubados a $30^{\circ} \mathrm{C}$ a sob agitação orbital $(170 \mathrm{rpm})$ por $72 \mathrm{~h}$. A biomassa imobilizada foi separada do meio de cultura por filtração a vácuo, lavada com água e acetona e seca em bomba de alto vácuo. 


\subsection{Sistema Contínuo}

As reações de transesterificação em fluxo contínuo foram realizadas em reatores de leito fixo com dimensões diferentes: Reator A (diâmetro interno $=45 \mathrm{~mm}$, comprimento $=190 \mathrm{~mm}$ e volume total $=310$ ); Reator B (diâmetro interno $=30 \mathrm{~mm}$, comprimento $=420 \mathrm{~mm}$ e volume total $=$ $300 \mathrm{~cm}^{3}$ ), operando numa vazão de $0,07 \mathrm{~mL} / \mathrm{min}$, por 16 dias. A mistura reacional composta por óleo de coco e etanol (razão molar 1:6, 1:8 e 1:10 óleo/etanol) e terc-butanol como solvente foi mantida a $35^{\circ} \mathrm{C}$. A coluna foi empacotada com $15 \mathrm{~g}$ de células imobilizadas (densidade média de $1,077 \pm 0,062 \mathrm{~g} / \mathrm{cm}^{3}$ ) correspondendo a um volume útil de $293 \mathrm{~cm}^{3}$ (reator A) e $285 \mathrm{~cm}^{3}$ (reator B). O esquema do sistema é apresentado na Figura 1. O monitoramento do processo foi efetuado pela quantificação dos ésteres de etila formados por cromatografia gasosa e a viscosidade dos ésteres purificados.



Figura 1. Esquema simplificado do reator de leito fixo: 1- Tanque de alimentação com agitação magnética, 2- Bomba peristáltica, 3Banho termostático, 4- Circulação de água, 5Coluna, 6- Saída de produto.

Reator A (relação $l / d)=190 / 45=4,2$

Reator B (relação $l / d)=420 / 30=14$

\subsection{Metodologia Analítica}

A atividade enzimática das células imobilizadas foi determinada pelo método modificado de hidrólise do azeite de oliva (Andrade et al., 2012). A umidade das células íntegras imobilizadas foi determinada em balança de secagem acoplada a lâmpada de infravermelho (Marte, Modelo ID 50). Os ésteres de etila foram monitorados por cromatografia de fase gasosa (Varian 3800) (Urioste et al., 2008). Para a separação da glicerina liberada na síntese do biodiesel, o meio reacional foi submetido a uma etapa de purificação, constituída basicamente de três lavagens com água destilada. Os valores da viscosidade absoluta dos produtos purificados foram medidos a $40^{\circ} \mathrm{C} \mathrm{em}$ viscosímetro (Brookfield, Modelo LVDVII) empregando o cone CP 42. A determinação dos teores de monoglicerídeos e diglicerídeos foi realizada por cromatografia líquida de alta eficiência (CLAE). 


\section{RESULTADOS E DISCUSSÃO}

\subsection{Influência da razão molar}

A influência da concentração molar dos componentes da mistura reacional na síntese de biodiesel em fluxo contínuo utilizando células íntegras imobilizadas em poliuretano foi verificada para diferentes proporções molares de óleo para etanol (1:6, 1:8 e 1:10). Nesta série de experimentos foi utilizado o Reator A (volume útil de $293 \mathrm{~cm}^{3}$ e tempo espacial de 70 horas) durante um período de 16 dias. A formação dos ésteres na etanólise do óleo de coco em fluxo contínuo em diferentes condições operacionais, mostrado na Figura 2, indicou diferentes desempenhos em função da razão molar do substrato.

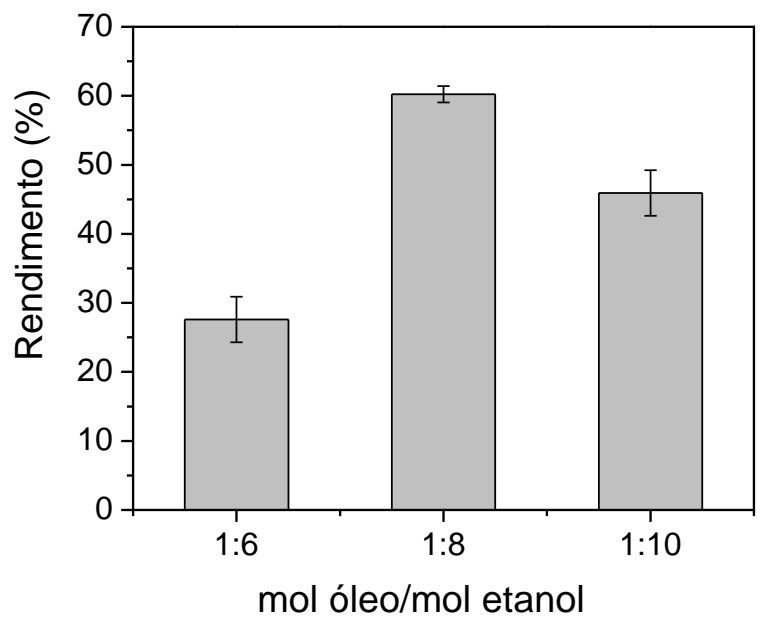

Figura 2. Influência da concentração molar dos componentes da mistura reacional na síntese de biodiesel em reator de leito fixo em fluxo contínuo (reator A).

Comparando-se os resultados obtidos verifica-se que o menor rendimento $(<30 \%)$, foi obtido no processo que utilizou o meio de alimentação na razão molar igual a 1:6. É provável que a viscosidade mais elevada deste substrato tenha limitado a dispersão homogênea do meio no reator. Entretanto a condição operacional que proporcionou maior excesso de etanol, razão molar (1:10), provocou também um declínio no rendimento das reações, pois, embora um excesso de álcool em relação à quantidade estequiométrica é normalmente requerido para deslocar o equilíbrio da reação em direção à formação de ésteres, uma grande quantidade em excesso de etanol pode inibir a atividade de algumas lipases (Stamenkovic et al., 2011). Conversões mais elevadas (da ordem de 62\%) foram alcançadas empregando a razão molar 1:8. Todo o sistema mostrou-se estável, não sendo constatado decaimento na conversão em ésteres etílicos em função do tempo reacional, exceto às oscilações inerentes ao sistema. A estabilidade do derivado imobilizado recuperado foi determinada ao final do experimento, não sendo constatada redução da atividade catalítica do biocatalisador. Entretanto, foram detectados caminhos preferenciais no sistema operacional (Reator A) provavelmente devido a limitações de transferência de massa e calor, refletida, por exemplo, pela relação geométrica do reator (altura/diâmetro=4,2), o que justifica a baixa conversão em ésteres de etila. 


\subsection{Influência da dimensão do reator}

Visando aumentar a conversão em ésteres de etila, o desempenho do processo foi avaliado empregando reator de leito fixo com diferente relação geométrica $(l / d=14)$. Utilizando o reator B, o experimento foi iniciado pelo empacotamento de 15,0 gramas (atividade inicial $=58,39 \mathrm{U} / \mathrm{g}$ ) formando uma coluna empacotada com carregamento catalítico total de 1101 unidades de atividade. A alimentação do substrato na razão molar 1:8 (óleo de coco:etanol) foi efetuada em fluxo ascendente na vazão de $0,07 \mathrm{~mL} \cdot \mathrm{min}^{-1}$, correspondendo a tempo espacial de 68 horas. A Figura 3 apresenta o comportamento dinâmico da concentração total em ésteres de etila, produto da reação enzimática, com oscilações inerentes a este tipo sistema, obtendo-se concentração média de ésteres de etila de $54,5 \pm 1,4 \%\left(\mathrm{~m} \cdot \mathrm{m}^{-1}\right)$.

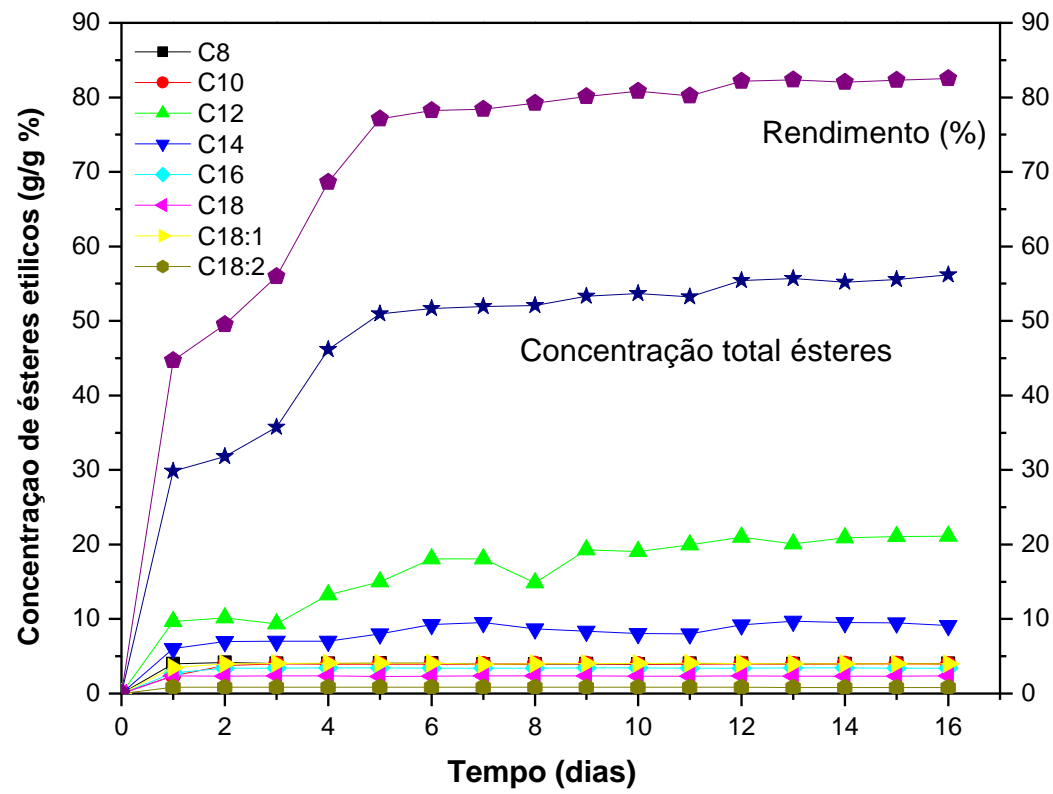

Figura 3. Concentração total em ésteres de etila obtida na etanólise enzimática do óleo de coco em reator de leito fixo operando em modo contínuo (temperatura $35^{\circ} \mathrm{C}$, razão molar $1: 8$ (óleo:etanol), tempo espacial de 68 horas.

Em se tratando de rendimento médio de transesterificação, o reator B ainda forneceu níveis inferiores aos obtidos no sistema descontínuo (Andrade et al., 2012), entretanto constata-se um aumento marcante na concentração de ésteres de etila em relação aos dados obtidos no reator A. $\mathrm{Na}$ Tabela 1 são apresentados os parâmetros do processo alcançados em ambos os reatores.

A eficiência na utilização de sistemas contínuos foi também alcançada por Yoshida et al., (2012) que utilizaram células íntegras na produção de biodiesel em fluxo contínuo com uma mistura de óleo de colza e soja, razão molar 1:4,25 (óleo: álcool), alcançando 96,1\% de rendimento de ésteres metílicos. Resultados satisfatórios também foram descritos por 
Hama et al., (2007), utilizando óleo de soja na razão molar 1:4 (óleo: álcool) com rendimentos de até $90 \%$ na produção de biodiesel com metanol em fluxo contínuo. Jin et al., (2008) empregaram células íntegras imobilizadas de $R$. oryzae em sistema contínuo para avaliar a eficiência de reações de transesterificação de óleo de canola utilizando etanol. Os autores alcançaram um rendimento de $66,1 \%$ em ésteres de etila, resultado inferior ao alcançado neste trabalho que também utiliza o etanol como agente acilante diferentemente dos demais estudos citados.

Tabela 1 - Quadro comparativo do desempenho do reator de leito fixo na etanólise contínua do óleo de coco mediada pela lipase de $M$. circinelloides URM 4182 imobilizada em poliuretano

\begin{tabular}{|c|c|c|}
\hline Parâmetros & Reator A $(1 / d=4,2)$ & Reator B $(\mathrm{l} / \mathrm{d}=14)$ \\
\hline Atividade inicial do biocatalisador $\left({\mathrm{U} . \mathrm{g}^{-1}}^{-1}\right)$ & 53,6 & 58,4 \\
\hline Constante de desativação $\left(\mathrm{k}_{\mathrm{d}}, \mathrm{h}^{-1}\right) \times 10^{3}$ & $35,3 \cdot 10^{-3}$ & $27,3.10^{-3}$ \\
\hline Tempo de meia-vida (h) & 19,6 & 25,4 \\
\hline Concentração de ésteres de etila $\left(\mathrm{g} \cdot \mathrm{g}^{-1}\right)$ & $47,4 \pm 5,9$ & $54,5 \pm 1,4$ \\
\hline Produtividade $\left(\mathrm{mg}_{\text {éster }} \cdot \mathrm{g}_{\text {meio }}{ }^{-1} \cdot \mathrm{h}^{-1}\right)$ & $37,7 \pm 4,2$ & $40,4 \pm 2,1$ \\
\hline Rendimento de transesterificação (\%) & $62,7 \pm 9,7$ & $82,7 \pm 3,2$ \\
\hline Viscosidade cinemática $40^{\circ} \mathrm{C}\left(\mathrm{mm}^{2} / \mathrm{s}\right)$ & $8,3 \pm 0,6$ & $6,9 \pm 0,6$ \\
\hline
\end{tabular}

Os teores de monoglicerídeos $(9,23 \pm 0,5 \mathrm{~m} / \mathrm{m} \%)$ e diglicerídeos $(3,45 \pm 0,3 \mathrm{~m} / \mathrm{m} \%)$ determinados por cromatográfica líquida confirmam a eficiência na síntese enzimática de monoésteres de etila. Entretanto, os resultados encontrados demonstram que o biodiesel obtido não atende os padrões estabelecidos pela legislação da ANP e sugerem a necessidade de estudos complementares do desempenho do processo em fluxo contínuo.

\section{CONCLUSÃO}

Por meio das condições experimentais analisadas, verificou-se que o melhor desempenho do sistema foi obtido no Reator B para o substrato constituído de óleo de coco: etanol e terc-butanol como solvente, numa razão molar de 1:8 e tempo espacial de $68 \mathrm{~h}$. Nessas condições, foram obtidos rendimentos de transesterificação médios de 82,5 $\pm 3,2 \%$ durante 16 dias de operação. Em todos os experimentos, a lipase do fungo $M$. circinelloides imobilizada em poliuretano foi estável quanto às suas características catalíticas. Embora o produto obtido (ésteres de etila) não atenda às características exigidas pelas normas para seu uso como biocombustível, a continuidade dos estudos de síntese de biodiesel em reator de leito fixo se mostra promissora diante das inúmeras variáveis que podem ser ainda otimizadas e das vantagens que este tipo de reator apresenta por conferir uma maior estabilidade ao biocatalisador.

\section{REFERÊNCIAS}

ANDRADE, G. S. S., FREITAS, L., OLIVEIRA, P. C., DE CASTRO H. F. Screening, immobilization and utilization of whole cell biocatalysts to mediate the ethanolysis of babassu oil. J Mol Catal B-Enzym., v. 84, p. 183-188, 2012. 
CHRISTOPHER, L. P.; KUMAR, H.; ZAMBARE, V. P. Enzymatic biodiesel: Challenges and opportunities, Appl. Energ., v. 119, p. 497-520, 2014.

FUKUDA, H.; KONDO, A.; TAMALAMPUDI, S. Bioenergy: Sustainable fuels from biomass by yeast and fungal whole-cell biocatalysts. Biochem. Eng. J, v. 44, p. 2-12, 2009.

HAMA, S.; YAMAJI, H.; FUKUMIZU, T.; NUMATA, T.; TAMALAMPUDI, S.; KONDO, A.; NODA, H.; FUKUDA, H. Biodiesel-fuel production in a packed-bed using lipase producing Rhizopus oryzae cells immobilized within biomass support particles. Biochem Eng J, v. 34, p. 273-278, 2007.

JIN, G.; BIERMA, T. J.; HAMAKER, C. G.; RHYKERD, R.; LOFTUS, L. A. Producing biodiesel using whole-cell biocatalysts in separate hydrolysis and methanolysis reactions. $J$. of Environ Sci and Health Part A, v. 43, p. 589-595, 2008.

KAPOOR, M.; GUPTA, M. N., Lipase promiscuity and its biochemical applications, Proc Biochem, v. 47 (4), p. 555-569, 2012.

SINGH, A. K.; MUKHOPADHYAY, M., Olive oil glycerolysis with the immobilized lipase Candida antarctica in a solvent free system, Grasas y Aceites, v. 63 (2), p. 202, 2012.

STAMENKOVIC, O. S.; VELICKOVIC, A. V.; VELJKOVIC, V. B. The production of biodiesel from vegetable oils by ethanolysis: Current state and perspectives. Fuel, v. 90, p. 3141-3155, 2011.

SUBHASH, G. V.; MOHAN, S. V. Biodiesel production from isolated oleaginous fungi Aspergillus sp. using corncob waste liquor as a substrate. Bioresour Technol, v. 102, p. 9286-9290, 2011.

URIOSTE, D.; CASTRO, M. A. B.; BIAGGIO, F. C.; DE CASTRO, H. F. Síntese de padrões cromatográficos e estabelecimento de métodos para dosagem da composição de ésteres de ácidos graxos presentes no biodiesel a partir do óleo de babaçu. Quím Nova, v. 31, p. 407412, 2008.

YOSHIDA, A.; HAMA, S.; TAMADANI, N.; FUKUDA, H.; KONDO, A. Improved performance of a packed-bed reactor for biodiesel production through whole-cell biocatalysis employing a high-lipase-expression system. Biochem. Eng. J, v. 63, p. 76-80, 2012.

YOSHIDA, A.; HAMA, S.; TAMADANI, N.; NODA, H.; FUKUDA, H.; KONDO, A. Continuous production of biodiesel using whole-cell biocatalysts: Sequential conversion of an aqueous oil emulsion into anhydrous product. Biochem. Eng. J., v. 68, p. 7- 11, 2012. 